\title{
A high-throughput method for genotyping S-RNase alleles in apple
}

\author{
Bjarne Larsen • Marian Ørgaard • \\ Torben Bo Toldam-Andersen • Carsten Pedersen
}

Received: 15 October 2015/Accepted: 8 February 2016/Published online: 19 February 2016

(C) The Author(s) 2016. This article is published with open access at Springerlink.com

\begin{abstract}
We present a new efficient screening tool for detection of S-alleles in apple. The protocol using general and multiplexed primers for PCR reaction and fragment detection on an automatized capillary DNA sequencer exposed a higher number of alleles than any previous studies. Analysis of alleles is made on basis of three individual fragment sizes making the allele interpretation highly accurate. The method was employed to genotype 432 Malus accessions and exposed 25 different S-alleles in a selection of Malus domestica cultivars of mainly Danish origin (402 accessions) as well as a selection of other Malus species (30 accessions). The allele S3 (28\%) was the
\end{abstract}

Data archiving statement S-RNase allele sequences from the apple cultivars Vejløæble (S33), Ydun (S36) and Boiken (S40) that are new for Malus domestica in GenBank are submitted to GenBank (KT751305, KT751304, and KT751306). All accessions and accession numbers are given in Supplementary material S2.

Electronic supplementary material The online version of this article (doi:10.1007/s11032-016-0448-0) contains supplementary material, which is available to authorized users.

B. Larsen ( $\square)$ - M. Ørgaard · T. B. Toldam-Andersen .

C. Pedersen

Department of Plant and Environmental Sciences,

University of Copenhagen, Thorvaldsensvej 40, 3rd Floor,

1871 Frederiksberg C, Denmark

e-mail: bj1@plen.ku.dk most common among the Danish cultivars followed by S1 and S7 (both $27 \%$ ). The alleles S36 and S40 not previously reported from $M$. domestica were found in 6 and 17 cultivars, respectively. Complete allelic composition was found in $91 \%$ of the 369 diploid accessions and in $86 \%$ of the 63 triploids concerned. We further identified a relatively high frequency of S33 and S34, which has not been considered by most previous studies. The protocol presented here is easy to adopt and saves both time and work effort compared to previous methods. The robustness is illustrated by the great accuracy and a high number of S-alleles presented.

Keywords S-RNase alleles $\cdot$ Apple $\cdot$ Malus domestica $\cdot$ Breeding $\cdot$ Compatibility $\cdot$ Fragment analysis

\section{Introduction}

Self-incompatibility in apple (Malus sp.) is controlled by an S-locus with a number of self-incompatibility alleles (Kobel et al. 1939). In this S-RNase-based gametophytic self-incompatibility system, pollen is able to inhibit stigmatic S-RNase, except in case of pollen-bearing $\mathrm{S}$-alleles identical to those in the stigma (De Franceschi et al. 2012). Variation in $\mathrm{S}$-alleles among genotypes grown in orchards is crucial to ensure fertilization and thereby a 
stable fruit yield. Although small-fruited Malus species often are used as pollinators in commercial orchards, compatibility among apple (M. domestica Borkh.) cultivars is often important in private gardens. Also in breeding programmes where selection for traits linked to specific S-alleles may occur, there is a risk that certain $\mathrm{S}$-alleles becomes more frequent along generations and that incompatibility problems can be faced.

Incompatibility studies among cultivars have traditionally been carried out by cross-pollination experiments which are highly time consuming and labour expensive. Obtained data from such studies can further be difficult to interpret since it can be difficult to discriminate between full-compatible and semi-compatible genotypes. Molecular studies have been carried out using either allele-specific primers to amplify the S-RNase allele (Broothaerts 2003; Broothaerts et al. 2004; Dreesen et al. 2010; Kim et al. 2006, 2009; Matsumoto and Kitahara 2000; Nybom et al. 2008) or allele-specific restriction enzymes after PCR amplification with universal primers as in the CAPS assay (Kim et al. 2009; Matsumoto and Kitahara 2000). In these studies the DNA fragment sizes were detected on an agarose gel. The CAPS assay requires a rather large selection of restriction enzymes and many equivalent reactions. Allele-specific primers likewise require one reaction per allele, and a large number of PCR reactions should be performed which costs time and money. Furthermore, such studies only expose alleles which were considered at the design and selection phase of appropriate primers; this procedure may prevent possibilities for detection of non-considered alleles present in the gene pool. Finally, conventional fragment base-pair length estimations on agarose gels give an approximate size and do not permit elusive identification of some S-RNase alleles.

Here we present a new high-throughput protocol for detection of S-RNase alleles using general and multiplexed primers, common restriction enzymes and accurate fragment length detection. The fragment analysis pipeline is fully equivalent to that of SSRmarkers and thus easy to adopt. As proof of concept, we present the results of genotyping 432 apple genotypes, covering the Danish apple (Malus domestica) cultivar collection (334 cultivars) together with a number of mainly European cultivars as well as selections of other Malus species, especially Malus sieversii and M. sylvestris.

\section{Materials and methods}

Plant material

Plant material was obtained from the gene bank collection at The Pometum (University of Copenhagen, Taastrup, Denmark). Fresh leaf material was collected from vigorously growing shoots and freezedried for $48 \mathrm{~h}$. DNA was extracted using DNeasy Plant Mini Kit (Qiagen, Hilden, Germany), following the manufacturers protocol. Samples were diluted to the concentration $2 \mathrm{ng} / \mu \mathrm{L}$.

\section{DNA amplification}

We combined the general forward primer ASPF3 (Kim et al. 2006) with the new reverse primer EIIWPN-R (Table 1) to amplify most of the described $\mathrm{S}$-RNase sequences. The forward primer always contained the M13-tail for fluorescence detection according to Schuelke (2000). This primer combination was found to be the best for amplifying most $\mathrm{S}$-RNase sequences after testing the forward primers ASPF3, PSNKNGP-F and HGLWPS-F in all combinations with the reverse primers EIIWPN-R, KQNVSEI-R and ASPR3S (Table 1; supplementary file S1). For S-RNase gene fragments yielding a length of more than $1000 \mathrm{bp}$ as well as fragments with unique annealing sites, we designed reverse primers to amplify S3, S5, S10, S39 and S47 (S3/S5/S10-R) and furthermore a specific reverse primer to amplify S16 (S16-R) and S25 (S25-R), respectively. These three reverse primers were used in a multiplex reaction with ASPF3 as forward primer. For S8 a specific forward (S8-F) was developed with two T's in the 3-prime end specific for the S8-sequence and with the M13-tail for fluorescence detection. The reverse (S8R) primer was developed for the hypervariable region before the intron position and also specific for the S8sequence (Table 1; supplementary file S1). All new primers were developed based on sequence alignments as shown in supplementary file S1 using Primer3Plus (Untergasser et al. 2007) and subsequently tested for efficient amplification.

PCR amplification was carried out in a thermal cycler in $20 \mu \mathrm{L}$ reaction mixture containing $10 \mathrm{ng}$ DNA, $1 \times$ Key Buffer $\left(10 \times\right.$ Key Buffer, VWR ${ }^{\circledR}$ International, Radnor, Pennsylvania, USA), $1.25 \mathrm{mM}$ $\mathrm{MgCl}_{2}, 0.2 \mu \mathrm{M} \mathrm{dNTP}, 0.05 \mu \mathrm{M}$ forward primer, 
Table 1 Primers for S-RNase allele amplification used in this study

\begin{tabular}{|c|c|c|c|c|}
\hline Primer & Primer sequence & Amplified S-RNase alleles & $\begin{array}{l}\text { Combine } \\
\text { primer } \\
\text { with }\end{array}$ & $\begin{array}{l}\text { PCR } \\
\text { protocol }\end{array}$ \\
\hline \multicolumn{5}{|c|}{ Reverse primers } \\
\hline EIIWPN-R & ACGTTYGGCCAAATAATWDCC & $\begin{array}{l}\text { S1, S2, S4, S6, S7, S9, S11, } \\
\text { S20, S21, S23, S24, S26, } \\
\text { S28, S31, S33, S34, S36, S40 }\end{array}$ & ASPF3-F & A \\
\hline $\begin{array}{l}\mathrm{S} 3 / \mathrm{S} 5 / \\
\mathrm{S} 10-\mathrm{R}\end{array}$ & $\begin{array}{l}\text { TGTTTTGAATYGAAAAT } \\
\text { TARTTAGGAGT }\end{array}$ & S3, S5, S10, S39, S47 & ASPF3-F & $\mathrm{B}$ \\
\hline S16-R & TGGAAGAGGGCAATTTTGG & S16 & ASPF3-F & $\mathrm{B}$ \\
\hline S25-R & TGAAAATGGCTGAAAAACTTTG & $\mathrm{S} 25$ & ASPF3-F & B \\
\hline S8-R & ATTTAAGGTTGTTTCTTTGCAATAC & S8 & S8-F & $\mathrm{B}$ \\
\hline \multicolumn{5}{|c|}{ Forward primers ${ }^{\mathrm{a}}$} \\
\hline ASPF3-F & (M13)-CAATTTACGCAGCARTATCAG & & & \\
\hline S8-F & (M13)-TACGATTATTTTCAATTTACGCTT & & & \\
\hline
\end{tabular}

${ }^{a}$ The forward primers contained the M13-tail: CACGACGTTGTAAAACGAC

$0.4 \mu \mathrm{M}$ reverse primer, $0.25 \mu \mathrm{M}$ M13 fluorochromelabelled M13 primer and 0.5 units $\mathrm{VWR}^{\circledR} \mathrm{Taq}$ polymerase. The three primers S3/S5/S10-R, S16-R and $\mathrm{S} 25-\mathrm{R}$ were used in a multiplex reaction with ASPF3 as forward primer. The multiplex reaction was carried out in a reaction mixture identical to the one described above, although using $0.2 \mu \mathrm{M}$ of each of the three reverse primers. During amplification, the products was labelled with FAM, VIC or NED (Schuelke 2000), using the fluorochrome-labelled M13 primer (CACGACGTTGTAAAACGAC) that fits the amplification products and was incorporated in the product during amplification.

PCR program A (Table 1) was initiated with 2 min at $94{ }^{\circ} \mathrm{C}$, and thereafter 18 "touchdown" cycles of $1 \mathrm{~min}$ at $94{ }^{\circ} \mathrm{C}, 30 \mathrm{~s}$ at $62{ }^{\circ} \mathrm{C}$ for the first cycle and decreasing with $0.5^{\circ} \mathrm{C}$ for each cycle and $3 \mathrm{~min}$ at $72{ }^{\circ} \mathrm{C}$, afterwards 20 cycles at $94{ }^{\circ} \mathrm{C}$ for $1 \mathrm{~min}, 53{ }^{\circ} \mathrm{C}$ for $1 \mathrm{~min}, 72{ }^{\circ} \mathrm{C}$ for $3 \mathrm{~min}$, and then finally $72{ }^{\circ} \mathrm{C}$ for $10 \mathrm{~min}$ and storage at $4{ }^{\circ} \mathrm{C}$.

PCR program B (Table 1) started with $2 \mathrm{~min}$ at $94{ }^{\circ} \mathrm{C}$, followed by 33 cycles of $94{ }^{\circ} \mathrm{C}$ for $20 \mathrm{~s}, 58{ }^{\circ} \mathrm{C}$ for $20 \mathrm{~s}, 72{ }^{\circ} \mathrm{C}$ for $2 \mathrm{~min}$ and finally $72{ }^{\circ} \mathrm{C}$ for $5 \mathrm{~min}$ before storage at $4{ }^{\circ} \mathrm{C}$.

Fragment digestion

All amplification products were analysed both undigested and after being digested with either RsaI or $T a q^{\alpha}$ I (New England Biolabs, Ipswich, MA, USA).
The two restriction enzymes were selected as being suitable for discriminating between the S-alleles (Table 2) after in silico analysis comparing various restriction enzymes. However, products amplified with the primer set S8-F and S8-R were not digested since the primer pair was designed to only amplify the S8-locus, and digestion was therefore not necessary to interpret results. We mixed $2 \mu \mathrm{L}$ PCR product with $1 \times$ CutSmart $^{\circledR}$ Buffer and 10 units restriction enzyme. Digestion with $R s a \mathrm{I}$ was carried out for $3 \mathrm{~h}$ at $37{ }^{\circ} \mathrm{C}$ followed by $65{ }^{\circ} \mathrm{C}$ for $20 \mathrm{~min}$ before storage at $4{ }^{\circ} \mathrm{C}$. Digestion with $\operatorname{Taq}^{\alpha} \mathrm{I}$ was carried out at $65^{\circ} \mathrm{C}$ for $3 \mathrm{~h}$ followed by $80{ }^{\circ} \mathrm{C}$ for $20 \mathrm{~min}$ and storage at $4{ }^{\circ} \mathrm{C}$.

Fragment length analysis

Three products with different fluorochrome labels were mixed and diluted 12 times before $2 \mu \mathrm{L}$ was added to a final solution of $12 \mu \mathrm{L}$ loading buffer ( $1 \mathrm{~mL} 0.1 \times$ TE-buffer and $40 \mu \mathrm{L}$ of an internal ROX size standard ranging from 58 to $948 \mathrm{bp}$ ). For each cultivar both undigested PCR products and $\operatorname{Taq}^{\alpha} \mathrm{I}$ - and $R s a \mathrm{I}$-digested products were analysed. Fragment lengths were detected by ABI 3130xl DNA analyser (Applied Biosystems, Foster City, CA, USA). Analysis and determination of band sizes were performed by the software GeneMarker ${ }^{\circledR}$ v. 2.2.0 (SoftGenetics ${ }^{\circledR}$ LLC, State College, PA, USA), based on an internal ROX-labelled size standard added to each sample. Each band was subsequently checked manually. 
Table 2 Fragment lengths after amplification with the primers given in Table 1 and digestion with restriction enzymes RsaI and $\operatorname{Taq}^{\alpha} \mathrm{I}$. Calculated and observed fragment lengths are given. Indicated values are inclusive the $19 \mathrm{bp}$ length of the fluorescent M13 tail. Where nd indicated the length that was not determined. 'Reference cultivar' indicates the cultivar from which the GenBank sequences are obtained, and 'Sequenced sample' is cultivar we sequenced to confirm the allele sequence

\begin{tabular}{|c|c|c|c|c|c|c|c|c|c|}
\hline \multirow[t]{3}{*}{ Allele } & \multicolumn{6}{|c|}{ Fragment length } & \multirow{3}{*}{$\begin{array}{l}\text { GenBank } \\
\text { accession }\end{array}$} & \multirow{3}{*}{$\begin{array}{l}\text { Reference } \\
\text { cultivar }\end{array}$} & \multirow{3}{*}{$\begin{array}{l}\text { Sequenced } \\
\text { sample }\end{array}$} \\
\hline & \multicolumn{2}{|c|}{ Undigested } & \multicolumn{2}{|c|}{ RsaI digested } & \multicolumn{2}{|c|}{ TaqI digested } & & & \\
\hline & Expected & Observed & Expected & Observed & Expected & Observed & & & \\
\hline \multicolumn{10}{|c|}{ General S-RNase allele primers: ASPF3-F + EIIWPN-R } \\
\hline $\mathrm{S} 1$ & 560 & $559-562$ & 223 & $119-222$ & 125 & $120-124$ & EU427454.1 & Fuji & $\begin{array}{l}\text { Adams } \\
\text { Pearmain }\end{array}$ \\
\hline $\mathrm{S} 2$ & 369 & $370-372$ & 369 & $370-371$ & 130 & $127-129$ & DQ219464.1 & M. domestica & Prima \\
\hline $\mathrm{S} 3$ & 1513 & nd & 210 & nd & 262 & nd & EU427455.1 & Elstar & \\
\hline $\mathrm{S} 4$ & 359 & $361-362$ & 295 & 294-296 & 326 & $328-330$ & EU427456.1 & Gloster & Fejø Æble \\
\hline S5 & 1381 & 1023-1032 & 423 & $424-426$ & 371 & $369-272$ & EU427460.1 & Elstar & \\
\hline S6 & 389 & $390-392$ & 389 & $390-392$ & 389 & 390-392 & EU427461.1 & $\begin{array}{l}\text { Citron } \\
\text { d'Hiver }\end{array}$ & $\begin{array}{l}\text { M.sieversii GS } \\
03-11\end{array}$ \\
\hline S7 & 340 & $340-342$ & 340 & $340-341$ & 125 & $122-124$ & EU427457.1 & Idared & Pigeon Ildrød \\
\hline S8 & nd & nd & nd & nd & nd & nd & AY744080.1 & $\begin{array}{l}\text { Ontario } \\
\text { mRNA! }\end{array}$ & \\
\hline S9 & 366 & $367-369$ & 366 & $367-369$ & 366 & $367-369$ & AB270792.1 & Florina & Dumelow \\
\hline S10 & 1940 & nd & 412 & nd & 898 & nd & AB428428.1 & Maypole & \\
\hline S11 & 394 & $395-398$ & 221 & $218-220$ & 152 & $149-152$ & FJ008669.1 & M. domestica & Guldborg \\
\hline S16 & 2813 & nd & 967 & nd & 166 & nd & AB428429.1 & Maypole & \\
\hline $\mathrm{S} 20$ & 533 & $535-537$ & 225 & $220-222$ & 125 & $121-123$ & EU427458.1 & Indo & $\begin{array}{l}\text { Tønnes, } \\
\text { Gravensteiner }\end{array}$ \\
\hline $\mathrm{S} 21$ & 396 & $398-399$ & 64 & $57-59$ & 363 & $366-368$ & AB094494.1 & $\begin{array}{l}\text { Ribston } \\
\text { Pippin }\end{array}$ & \\
\hline $\mathrm{S} 23$ & 369 & $367-368$ & 369 & $367-368$ & 21 & $233-234$ & AF239809.1 & Granny Smith & \\
\hline $\mathrm{S} 24$ & 556 & $556-558$ & 444 & $446-448$ & 125 & $122-124$ & HQ693065.1 & Harangalma & \\
\hline $\mathrm{S} 25$ & 2582 & nd & 625 & nd & 1523 & nd & AB428431.1 & McIntosh & \\
\hline S26 & 379 & 381 & 379 & 381 & 379 & 381 & EU427459.1 & David & Ulderupæble \\
\hline $\mathrm{S} 28$ & 391 & $392-394$ & 227 & $223-225$ & 391 & $392-394$ & HQ693074.1 & Gyogyi piros & $\begin{array}{l}\text { Citronæble, } \\
\text { Ørdings Æble }\end{array}$ \\
\hline $\mathrm{S} 29$ & 448 & nd & 193 & nd & 415 & nd & AY039702.1 & Anna & \\
\hline $\mathrm{S} 31$ & 493 & $496-497$ & 223 & $220-221$ & 125 & $120-124$ & DQ135990.1 & $\begin{array}{l}\text { York } \\
\text { Imperial }\end{array}$ & $\begin{array}{l}\text { Langt Rødt } \\
\text { Hindbæræble }\end{array}$ \\
\hline S32 & 373 & nd & 64 & nd & 373 & nd & DQ135991.1 & Burgundy & \\
\hline S33 & 960 & $946-948$ & 569 & $565-567$ & 960 & $947-948$ & AB540121.1 & M. sieversii & Vejløæble \\
\hline S34 & 1040 & $977-980$ & 622 & $618-620$ & 1040 & $976-977$ & AB540122.1 & $\begin{array}{c}\text { Adersleber } \\
\text { Calville }\end{array}$ & $\begin{array}{l}\text { Spiseæble fra } \\
\text { Vejle }\end{array}$ \\
\hline S36 & 399 & $402-403$ & 64 & $57-58$ & 366 & $370-371$ & EU419865.1 & M. sylvestris & Ydunsæble \\
\hline S37 & 386 & nd & 227 & nd & 386 & nd & EU419864.1 & M. sylvestris & \\
\hline S38 & 383 & nd & 227 & nd & 350 & nd & EU419863.1 & M. sylvestris & \\
\hline S39 & 1658 & nd & 445 & nd & 725 & nd & EU419871.1 & M. sylvestris & \\
\hline $\mathrm{S} 40$ & 367 & $368-370$ & 303 & 301-304 & 334 & $336-338$ & EU419869.1 & M. sylvestris & Boiken \\
\hline S42 & 2025 & nd & 604 & nd & 2025 & nd & EU427453.1 & Murray & \\
\hline $\mathrm{S} 44_{\text {syl }}$ & 934 & nd & 567 & nd & 934 & nd & EU419862.1 & M. sylvestris & \\
\hline $\mathrm{S} 44_{\text {dom }}$ & 396 & nd & 64 & nd & 363 & nd & FJ008673.1 & M. domestica & \\
\hline $\mathrm{S} 45_{\text {syl }}$ & 1364 & nd & 405 & nd & 1080 & nd & EU419861.1 & M. sylvestris & \\
\hline
\end{tabular}


Table 2 continued

\begin{tabular}{|c|c|c|c|c|c|c|c|c|c|c|c|c|}
\hline \multirow[t]{3}{*}{ Allele } & \multicolumn{9}{|c|}{ Fragment length } & \multirow{3}{*}{$\begin{array}{l}\text { GenBank } \\
\text { accession }\end{array}$} & \multirow{3}{*}{$\begin{array}{l}\text { Reference } \\
\text { cultivar }\end{array}$} & \multirow{3}{*}{$\begin{array}{l}\text { Sequenced } \\
\text { sample }\end{array}$} \\
\hline & \multicolumn{2}{|c|}{ Undigested } & \multicolumn{4}{|c|}{ RsaI digested } & \multicolumn{3}{|c|}{ TaqI digested } & & & \\
\hline & Expected & Observed & \multicolumn{2}{|c|}{ Expected } & \multicolumn{2}{|c|}{ Observed } & \multicolumn{2}{|c|}{ Expected } & Observed & & & \\
\hline $\mathrm{S} 45_{\text {sou }}$ & 534 & nd & 224 & & nd & & 502 & & nd & FJ008671. & M. soulardii & \\
\hline $\mathrm{S} 46_{\text {syl }}$ & 692 & nd & 221 & & nd & & 659 & & nd & EU419860 & $.1 \quad M$. sylvestris & \\
\hline $\mathrm{S} 46_{\text {sou }}$ & 365 & nd & 365 & & nd & & 365 & & nd & FJ008672. & M. soulardii & \\
\hline $\mathrm{S} 47_{\text {syl }}$ & 1307 & nd & 422 & & nd & & 172 & & nd & EU419859 & $.1 \quad M$. sylvestris & \\
\hline \multirow[t]{2}{*}{ Allele } & \multicolumn{2}{|l|}{ Undigested } & \multicolumn{3}{|c|}{ RsaI digested } & \multicolumn{4}{|c|}{ TaqI digested } & \multirow{2}{*}{$\begin{array}{l}\text { GenBank } \\
\text { accession }\end{array}$} & \multirow{2}{*}{$\begin{array}{l}\text { Reference } \\
\text { cultivar }\end{array}$} & \multirow[t]{2}{*}{ Sequenced sample } \\
\hline & Expected & Observed & Expected & & oserved & $\mathrm{Ex}$ & pected & & served & & & \\
\hline \multicolumn{13}{|c|}{ Allele-specific primer assays: ASPF3-F + S3/S5/S10-R, S16-R and S25-R } \\
\hline $\mathrm{S} 3$ & 423 & $425-427$ & 210 & & $7-209$ & 26 & & & $0-264$ & EU427455.1 & Elstar & Guldspi, Mutsu \\
\hline S5 & 399 & $401-403$ & 399 & & $1-402$ & 273 & & & 9-273 & EU427460.1 & Elstar & Cox's Orange \\
\hline S10 & 380 & $382-383$ & 380 & & $1-383$ & 380 & & & $2-383$ & AB428428.1 & Maypole & Pigeon Ildrød \\
\hline S16a & 787 & nd & 787 & nd & & 168 & & nd & & AB428429.1 & Maypole & \\
\hline S16b & 469 & $469-470$ & 469 & & $9-470$ & 168 & & & $5-166$ & AB428430.1 & Alkmene & $\begin{array}{l}\text { Bismarck, Laxton's } \\
\text { Superb }\end{array}$ \\
\hline $\mathrm{S} 16 \mathrm{c}$ & 480 & 482 & 480 & 482 & & 168 & & 16 & & AB126322.1 & Bohnapfel & Ondrup Moseæble \\
\hline $\mathrm{S} 25$ & 490 & 493 & 490 & 493 & & 490 & & & $3-494$ & AB428431.1 & McIntosh & C. J. Hansen 603 \\
\hline S39 & 417 & nd & 417 & nd & & 417 & & nd & & EU419871.1 & M. sylvestris & \\
\hline S47 & 388 & nd & 388 & nd & & 17 & & nd & & EU419859.1 & M. sylvestris & \\
\hline \multicolumn{13}{|c|}{ Allele-specific primer: $S 8-\mathrm{F}+\mathrm{S} 8-\mathrm{R}$} \\
\hline S8 & 181 & $178-179$ & 76 & nd & & 131 & & nd & & AY744080.1 & $\begin{array}{l}\text { Ontario } \\
\text { mRNA! }\end{array}$ & $\begin{array}{l}\text { Bødkeræble, } \\
\text { Gadeskovæble, } \\
\text { James Grieve, } \\
\text { Signe Tillisch }\end{array}$ \\
\hline
\end{tabular}

The expected restriction fragment lengths of published S-RNase alleles from GenBank accessions (http://www.ncbi.nlm.nih.gov/genbank/) were calculated using CLC main workbench (CLC bio).

\section{Sequencing}

Selected samples were sequenced at GATC Biotech (Germany) after purification with Exonuclease I and Antarctic phosphatase (New England Biolabs). The sequences were compared with accessions of known S-RNase sequences at GenBank to confirm the identifications made based on fragment lengths. Reference cultivars were for example 'Adam's Pearmain' (S1, S3), 'Golden Delicious' (S2, S3), 'Gravensteiner' (S4, S11, S20), 'James Grieve' (S5, S8),
'Jonathan' (S7, S9), 'Cox's Orange' (S5, S9), 'Prima' (S2, S10), 'Laxton's Superb' (S5, S16b), 'Ribston (S1, S9, S21), 'Granny Smith' (S3, S23), 'Discovery' (S1, S24) and 'Red Delicious' (S9, S28). To confirm the results, we sequenced one sample for each S-RNase allele, and in all cases we found consensus between the allele we expected and identified.

Ploidy level

Ploidy levels given in Supplementary file 2 were determined by Larsen et al. (unpublished). For the great majority of accessions, including all Danish cultivars, determination was done by flow cytometry; for remaining accessions, ploidy level was determined from the number of alleles in 15 SSR loci. 


\section{Results}

A new high-throughput protocol for S-RNase allele genotyping

Initially we downloaded and aligned all available different S-RNase allele sequences from $M$. domestica and $M$. sylvestris in GenBank. Based on this we designed new primers and selected suitable restriction enzymes for discriminating all alleles (supplementary file S1). Genotyping of S-RNase alleles was done on basis of fragment lengths of both undigested fragments as well as fragments digested with $R s a \mathrm{I}$ and $T a q^{\alpha} \mathrm{I}$ restriction enzymes recognizing GTAC and TCGA, respectively. Only the fragment from the labelled forward primer to the first restriction site is detected on the sequencer simplifying the allele scoring. Calculated and observed fragment lengths are given in Table 2. The nomenclature of S-haplotypes follows the most recent of Matsumoto (2013).

The estimation of fragment sizes using the DNA sequencer and the GeneMarker software differed from the calculated fragment sizes with \pm 1 or 2 bp as indicated with the differences between 'expected' and 'observed' fragment lengths (Table 2). However, it was precise enough to draw unambiguous conclusions in each case. There are some S-RNase alleles, which are so similar that data from both $R s a \mathrm{I}$ and $T a q^{\alpha} \mathrm{I}$ digestion are needed such as S2 and S23, where both undigested PCR products are 369 bp long, and since there are no $R s a \mathrm{I}$-sites, the $T a q^{\alpha} \mathrm{I}$ digestion is necessary for discrimination.

The S8-allele has been neglected in most studies probably because it is not amplified with the most common general S-RNase primers due to two SNPs in the $3^{\prime}$-end of the ASPF3F annealing sequence. Because of that (Dreesen et al. 2010) developed S8allele-specific primers, which unfortunately did not work well under our conditions. The forward primer we developed has two unique T's in the $3^{\prime}$-end, and the reverse primer is placed in the hypervariable region before the intron and is also specific for the S8sequence (supplementary file S1). This allowed us to identify the S8-allele in 35 Danish cultivars.

Diversity in S-RNase alleles

Twenty-five different alleles were found among 432 accessions analysed (supplementary file S2). We analysed 369 diploid accessions of which we identified two S-RNase alleles in $91 \%$ of the samples. For the 63 triploid samples, we recognized at least two alleles in all samples and three alleles in $86 \%$ of the accessions. The most common alleles in the Danish cultivars were $\mathrm{S} 1, \mathrm{~S} 3$ and S7 which were present in more than $25 \%$ of the cultivars (Fig. 1). Also for the cultivars of mixed international origin considered, S3 (35\%) was the most common allele followed by $\mathrm{S} 1, \mathrm{~S} 5$ and $\mathrm{S} 9$ (all $>22 \%$ ).

\section{Discussion}

High-accuracy prediction of S-RNase alleles

A new protocol for detection and genotyping of $\mathrm{S}$-RNase alleles in apple is presented. It relies on a universal primer pair flanking the variable exon and hypervariable intron areas. Here, variation is detected either directly as length polymorphism of undigested products or after digestion with selected restriction enzymes recognizing polymorphic sites or creating unique restriction fragments. We predicted S-RNase alleles on basis of three different fragment lengths: undigested, RsaI-digested and $T a q^{\alpha}$ I-digested PCR products. We developed a new general reverse primer placed in a conserved sequence of the second exon to amplify shorter fragments. Some S-RNase alleles with large introns still have large amplicons, which are less efficiently amplified, so we developed three new reverse primers for S3, S5, S10, S16, S25, S39 and S47 for multiplexing PCR. Fragments are sized with high accuracy on a capillary sequencer, and fragments with almost identical lengths such as 391, 394 and 396 bp which were the calculated fragment lengths of S28, S11 and S2, respectively, were more or less distinguishable though the exact identification was done after digestion with two restriction enzymes, where much larger length polymorphisms were obtained. These were after RsaI digestion, 227, 221 and 64 bp, respectively, and 391, 152 and 363 bp, respectively, after $\operatorname{Taq}^{\alpha}$ I digestion.

Even though there was a small discrepancy of 1-3 bp between the calculated fragment lengths and detected fragment lengths, it was possible to make unambiguous interpretations of the obtained results. Such discrepancies of a few base pairs are common, especially between results obtained in different 


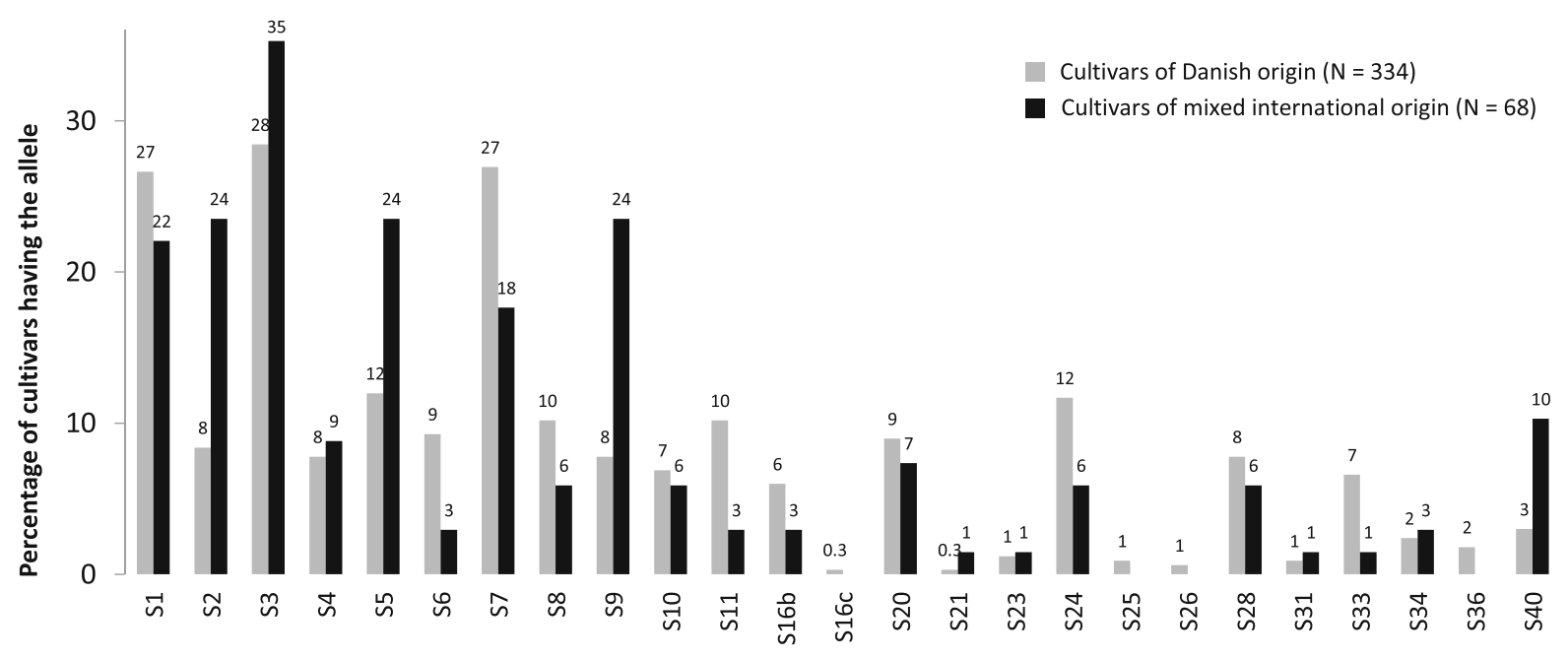

Fig. 1 Relative frequency of S-RNase alleles among studied cultivars

laboratories due to different equipment used. It is probably the relative discrepancies which do not influence interpretation of the results, as long as they are taken into consideration.

The genotyping approach presented here for apple can easily be applied in other species such as pears and cherries. The protocol is very similar to that for SSRmarkers, except for the inclusion of a restriction digestion step, making it is easy to adopt and implement in a SSR-marker laboratory.

\section{Efficiency of genotyping}

This protocol provide a reduced work load as three PCR reactions including general and specific primers were able to amplify 25 alleles. In comparison, to identify the same number of alleles by specific primers, 25 PCR reactions would have been needed. Even though our protocol involves an additional step of digesting PCR products with two restriction enzymes before analysis on a capillary sequencer, the method still implies a rationalization compared to previous methods in which analysis is made on individual agarose gels for each allele. Since the use of different fluorescence labelling of products enabled us to multiplex tree products, only one run on the capillary sequencer on average is needed per studied accession.

In studies were specific primers have been used, only a secection of primers have been considered which potentially leaves alleles that are rare or unexpected in the population to remain unexposed. Universal primers as used here, on the other hand, facilitate exposure of unexpected or unknown alleles. None the less, we still lack to expose one allele in a smaller part of the accessions studied here $(9 \%$ of the diploids and $14 \%$ of the triploids). A reason for this could be that PCR reaction favours amplification of some alleles, causing less efficiently amplified alleles to be sheltered, when present together. This effect may be extraordinary strong in triploids, where amplification may favour two alleles leaving the third allele not to be exposed. However, this is provided only if genotypes are heterozygous in the S-RNase allele locus, and it might be eventhough it is very rare, that some individuals descends from self-pollination and consequently could be homozygous.

We were able to identify 25 alleles among 432 accessions. In comparison, Nybom et al. (2008) reported 14 alleles, Broothaerts et al. (2004) 18 alleles, Halasz et al. (2011) 20 alleles and only Kim et al. (2009) reporting 22 alleles recorded alleles above S28. In the most recent revision of S-RNase alleles, Matsumoto (2013) lists 27 S-haplotypes, with S34 as the highest number. We identified 22 of these S-haplotypes in the Danish cultivar collection, in addition to S36 and S40. We did not identify S15 and S18 described by Bošković and Tobutt (1999) which nucleotide sequences are not reported (Broothaerts 2003). Further studies should reveal whether these are actually unique alleles or synonyms for other published alleles, by studying 'Kaiserapfel' and 
'Menzauer Jägerapfel' from where the two alleles respectively were described. We did not either find S30 described from the Chinese native Malus transitoria (Batalin) C.K. Schneid., or find S29 or S32 which were described from the Israeli cultivar 'Anna' and the American cultivar 'Burgundy', respectively. However, since the later cultivars have their origin outside Europe and only have been grown very little, if ever, in Denmark; it is not likely that they have contributed genetically to the Danish cultivars.

\section{Nomenclatural inconsistency}

In 2010 Long et al. described and named three S-RNase alleles: S44 from Malus domestica and S45 and S46 from M. soulardii. Later the same year, the three names were used again by Dreesen et al. (2010) who described several new S-RNase alleles from $M$. sylvestris under the names S36-S47. Whether these $\mathrm{S}$-RNases-sequences have unique functions is not yet known since some of them are rather similar to previously described S-RNases. Here, we followed the nomenclature of Matsumoto (2013) where the alleles were not considered, and until a proper nomenclature has been sorted out, we will use their given names with an abbreviation of the species name as appendix, so that $\mathrm{S} 44_{\mathrm{dom}}$ is different from S44 $4_{\text {syl }}$ (Table 2).

Rare S-RNase alleles among Danish cultivars

The rarest alleles among the Danish cultivars were S16c and S21, which were only found in 'Ondrup Moseæble' and 'Rød Melba', respectively. The S16c allele has previously only been reported from Bohnapfel (Bošković and Tobutt 1999) and S21 are also present in 'Ribston'.

Other rare alleles were S23 and S25 which most probably are inherited from the Australian 'Granny Smith' (S3, S23) and the Canadian 'McIntosh' (S10, S25) which on a worldwide scale has been widely grown but has played a minor role in Northern Europe. Eight Danish cultivars had S34 which probably descends from the English 'Cox's Pomona' and 'Queen' of which the first has been most commonly grown in Denmark and probably the main provider of the allele. S36 and S40 were previously described only from Malus sylvestris, but we identified it in a selection of $M$. domestica cultivars as well as a selection of M. sylvestris of Danish origin.
Diversity of S-RNase alleles in Danish apple cultivars

The three most common alleles, S1, S3 and S7, were more than twice as frequent as any other allele. On basis of S-RNase allele frequency among the Danish cultivars, we can divide the alleles into three groups: the common alleles S1, S3 and S7 $>27 \%$ of the cultivars), followed by S2, S4, S5, S6, S8, S9, S10, S11, S16b, S20, S24, S28, S33 (6-12\%) and the rare alleles S16c, S21, S23, S25, S26, S31, S34, S36, S40 $(<3 \%)$. In $13 \%$ of the cultivars the genotype was constituted exclusively of the three 'common' alleles, and at least one of the three alleles was represented in $68 \%$ of the cultivars. Similar to our findings, S3 and S7 were the two most common alleles found by Nybom et al. (2008) and Halasz et al. (2011) studying cultivars from primarily Northern Europe and the Carpathian basin, respectively.

Among European, American and Japanese cultivars, Broothaerts et al. (2004) also found the most frequent allele to be $S 3$, followed by $S 2$ and $S 9$. Dreesen et al. (2010) again found the most shared allele to be S3 followed by $\mathrm{S} 1$ and S5, whereas Matsumoto et al. (2007) found S1, S7 and S9 to be most common. Compared to the two later studies, Nybom et al. (2008) similar to our findings found a low frequency of S9. This was explained by the fact that 'Cox's Orange', 'Delicious' and 'Fuji' all having S9 are ancestors to many American, South European and Japanese cultivars, but have had a minor impact on cultivars grown in Northern Europe. Concerning 'Delicious' and 'Fuji', the reason is obviously lack of cultivation in Denmark; however, 'Cox's Orange' has been the most widely planted cultivar in Denmark during the majority of the twentieth century. From SSR-marker analysis (Larsen et al., unpublished), we found 'Cox's Orange' among the most frequent identified parents of the Danish cultivars; however, the great majority of these offspring bears the S5 allele from Cox's Orange.

According to Pedersen (1950), the main cultivars in Denmark in the 1930s were 'Belle de Boskoop' (S2, S3, S5), 'Bramley' (S3, S10, S40), 'Boiken' (S3, S40), 'Cox's Orange' (S5, S9), 'Cox's Pomona' (S1, S34), Filippa (S7, S24), 'Gravensteiner' (S4, S11, S20), 'Bellefleur de France' (S2, S7, S20), 'Ildrød Pigeon' (S7, S10), 'Pederstrup' (S1, S20) and 'Transparante Blanche' (S1). Among these, we find a high frequency 
of the most common alleles identified in the Danish cultivar collection. We found a relatively high presence of S4 (8\%) compared to both Broothaerts et al. (2004) and Halasz et al. (2011) who found S4 to be among the absolute rarest alleles. We also found a relatively high frequency of S11 (10\%) among the Danish cultivars compared to the cultivars of mixed international origin considered. The allele S8 was present in $10 \%$ of the Danish cultivars, probably inherited mainly from 'James Grieve'.

So far, S33 has only been reported from Malus sieversii (Ledeb.) M. Roem. and M. orientalis Uglitzk. The allele was described together with S34 by Matsumoto et al. (2010), and the alleles have unfortunately not been considered in most previous studies (Broothaerts et al. 2004; Halasz et al. 2011; Nybom et al. 2008). However, we found S33 in 22 Danish cultivars as well as in the English cultivar 'Beauty of Kent'. This cultivar has been grown in Denmark since around 1850 and the allele probably is inherited mainly here from.

Cultivars used as parents in breeding programmes differ around the world due to cultural preferences in taste, climate hardiness, etc. According to Laurens (1996), common cultivars in worldwide breeding programmes have to large extent been 'Braeburn' (S9, S24), 'Fuji' (S1, S9), 'Gala' (S2, S5), 'Golden Delicious' (S2, S3), 'Granny Smith' (S3, S23), 'Idared' (S3, S7), 'Jonathan' (S7, S9) and 'Red Delicious' (S9, S28). Their S-RNase alleles, except S23, are also the most common among the selection of apple cultivars of mixed international origin examined here (Fig. 1), but whether this is a coincidence is not sure. However, it shows that relatively few S-RNase alleles are common among many major cultivars. Among the Danish cultivars, we found a considerable diversity in S-RNase alleles. Breeding programmes should utilize this beautiful diversity and include breeding partners with some of the rarer S-RNase alleles, in oder to prevent potential incompability problems.

Acknowledgments We are grateful to a generous grant from Foreningen PlanDanmark that made the work possible and for a Ph.D. scholarship from the Department of Plant and Environmental Sciences.

\section{Compliance with ethical standards}

Conflict of interest The authors declare that they have no conflict of interest.
Open Access This article is distributed under the terms of the Creative Commons Attribution 4.0 International License (http:// creativecommons.org/licenses/by/4.0/), which permits unrestricted use, distribution, and reproduction in any medium, provided you give appropriate credit to the original author(s) and the source, provide a link to the Creative Commons license, and indicate if changes were made.

\section{References}

Bošković R, Tobutt KR (1999) Correlation of stylar ribonuclease isoenzymes with incompatibility alleles in apple. Euphytica 107:29-43

Broothaerts W (2003) New findings in apple S-genotype analysis resolve previous confusion and request the re-numbering of some S-alleles. Theor Appl Genet 106:703-714

Broothaerts W, Van Nerum I, Keulemans J (2004) Update on and review of the incompatibility (S-) genotypes of apple cultivars. HortScience 39:943-947

De Franceschi P, Dondini L, Sanzol J (2012) Molecular bases and evolutionary dynamics of self-incompatibility in the Pyrinae (Rosaceae). J Exp Bot 63:4015-4032

Dreesen RS, Vanholme BT, Luyten K, Van Wynsberghe L, Fazio G, Rold n-Ruiz I, Keulemans J (2010) Analysis of Malus S-RNase gene diversity based on a comparative study of old and modern apple cultivars and European wild apple. Mol Breed 26:693-709

Halasz J, Hegedus A, Gyorgy Z, Pallinger E, Toth M (2011) S-genotyping of old apple cultivars from the Carpathian basin: methodological, breeding and evolutionary aspects. Tree Genet Genomes 7:1135-1145

Kim H, Hattori G, Hirata Y, Kim D, Hwang J, Shin Y, Nou I (2006) Determination of self-locompatibility genotypes of Korean apple cultivars based on S-RNase PCR. J Plant Biol 49:448-454

Kim H, Kakui H, Kotoda N, Hirata Y, Koba T, Sassa H (2009) Determination of partial genomic sequences and development of a CAPS system of the S-RNasegene for the identification of $22 \mathrm{~S}$ haplotypes of apple (Malus domestica Borkh.). Mol Breed 23:463-472

Kobel F, Steinegger P, Anliker J (1939) Weitere Untersuchungen über die Befruchtungsverhältnisse der Apfel-und Birnsorten Landwirtschaftlichen. Jahrbuch der Schweiz 1939:160-191

Laurens F (1996) Review of the current apple breeding programmes in the world: objectives for scion cultivar improvement. In: Eucarpia symposium on fruit breeding and genetics, vol 484, pp 163-170

Long S, Li M, Han Z, Wang K, Li T (2010) Characterization of three new $S$-alleles and development of an S-allele-specific PCR system for rapidly identifying the S-genotype in apple cultivars. Tree Genet Genomes 6:161-168. doi:10.1007/ s11295-009-0237-6

Matsumoto S (2013) Database of S-RNase. http://www.agr. nagoya-u.ac.jp/ hort/apple/. Updated 19 July 2013

Matsumoto S, Kitahara K (2000) Discovery of a new self-incompatibility allele in apple. HortScience 35:1329-1332 
Matsumoto S, Eguchi T, Bessho H, Abe K (2007) Determination and confirmation of S-RNase genotypes of apple pollinators and cultivars. J Hortic Sci Biotechnol 82:323-329

Matsumoto S, Yamada K, Shiratake K, Okada K, Abe K (2010) Structural and functional analyses of two new S-RNase alleles, Ssi5 and Sad5, in apple. J Hortic Sci Biotechnol 85:131-136. doi:10.1080/14620316.2010.11512643

Nybom H, Sehic J, Garkava-Gustavsson L (2008) Self-incompatibility alleles of 104 apple cultivars grown in Northern Europe. J Hortic Sci Biotechnol 83:339-344
Pedersen A (1950) Danmarks Frugtsorter, 1. del. æbler. Alm. Dansk Gartnerforening, Copenhagen

Schuelke M (2000) An economic method for the fluorescent labeling of PCR fragments. Nat Biotechnol 18:233-234

Untergasser A, Nijveen H, Rao X, Bisseling T, Geurts R, Leunissen J (2007) Primer3Plus, an enhanced web interface to Primer3. Nucleic Acids Res 35:W71-W74. doi:10.1093/ nar/gkm306 